Madera, M. \& Acosta, R. (2017). Condiciones comerciales de la actividad artesanal y ecoturística del departamento de SucreColombia. Económicas CUC, 38(1), 79-104. DOI: http://dx.doi. org/10.17981/econcuc.38.1.04

\title{
Condiciones comerciales de la actividad artesanal y ecoturística del departamento de Sucre-Colombia ${ }^{1}$
}

\section{Commercial conditions of artisans and ecotourism activities of the department of Sucre, Colombia}

DOI: http://dx.doi.org/10.17981/econcuc.38.1.04

\author{
Maura Milena Madera Martínez ${ }^{2}$ \\ Raúl Ernesto Acosta Mesa ${ }^{3}$
}

\begin{abstract}
Resumen
El departamento de Sucre, Colombia, cuenta con un potencial turístico de atractivos artesanales y ecoturísticos que representan para su economía una fuente de ingresos significativa, no obstante, este segmento de negocio presenta limitaciones en la definición de planes estratégicos de competitividad, sistemas de calidad e inteligencias de mercado. Esta situación conlleva a analizar la inteligencia comercial de los sectores mencionados para conocer las condiciones actuales de mercado y determinar las propuestas para mejorar su competitividad. En el estudio se aplica una metodología cuantitativa de tipo descriptiva analítica. Con una muestra de 43 empresas artesanales en los municipios de Sampués y Morroa y un grupo de gestores de la actividad ecoturística en Colosó, se aplicaron las técnicas de observación, encuesta y entrevista semiestructurada. Asimismo, se desarrolla una contrastación a través de un benchmarking de las actividades objeto de estudio en la ciudad de Cartagena. Los resultados señalan la importancia de iniciar un plan de acción para generar competitividad en el sector.
\end{abstract}

Palabras clave: turismo; inteligencia comercial; competitividad comercial; artesanías; ecoturismo.

Recibido: 5/2/2017 Devuelto para revisión: 18/5/17 Aceptado: 22/5/2017.

\begin{abstract}
${ }^{1}$ Artículo resultado de la investigación titulada: "Análisis de inteligencia comercial y competitiva del turismo de artesanías de Sampués y Morroa y del ecoturismo en Colosó", en el marco del programa de formación de capacidades en ciencia, tecnología e innovación Gobernación de Sucre-CECAR.

${ }^{2}$ Licenciada en Contadora Pública. Joven investigadora. Convocatoria departamental jóvenes investigadores innovadores año 2015-2016 del programa de formación de capacidades en ciencia, tecnología e innovación Gobernación de Sucre-CECAR. Correo electrónico: mauram409@gmail.com

${ }^{3}$ Economista. Magister en Sociedad de la información y el Conocimiento. Profesor de la Facultad de Economía y Negocios, Universidad Tecnológica de Bolívar, Colombia. Director de Núcleo Problema del Programa de Formación de Capacidades en CT+I Gobernación de Sucre-CECAR. Correo electrónico: racosta@unitecnologica.edu.co
\end{abstract}

\footnotetext{
- The author; licensee Universidad de la Costa - CUC.
}

Económicas CUC vol. 38 no. 1, pp. 79-104. Enero - Junio, 2017

Barranquilla. ISSN 0120-3932 Impreso, ISSN 2382-3860 Online 


\begin{abstract}
Sucre is a department in the Caribbean Region of Colombia, which has a potential tourism of artisans as well ecotourism attractions that represent relevant sources of incomes for its economy, however, this business segment shows several limitations, with regard to the definition of strategic plans of competitiveness, quality systems and Market intelligence, this entails to analyze the business intelligence of the mentioned sectors in order to know the current market conditions to determine proposals that allow to improve their prospective of trades. Turning to the research methods a quantitative descriptive analytical methodology was used to carry out this work; the chosen sample in this research was a group of forty three artisanal companies in the municipalities of Samhora and Morroa and a group of managers of the ecotourism activities in Colosó, also techniques of observations, surveys and semi-structured interviews were applied. Likewise, a comparison research was developed through a benchmarking perspective focused on the subject of study in the city of Cartagena, Colombia. It can be said after have analyzed the obtained results that it is relevant to implement effective strategies addressed to create competitiveness in the mentioned sectors.
\end{abstract}

Keywords: tourism, business intelligence, commercial competitiveness, handicrafts, ecotourism.

\title{
Introducción
}

El departamento de Sucre, está integrado por subregiones que constituyen un gran potencial turístico, debido a la posición privilegiada en la que se encuentran y al acervo históricocultural que representan cada una de ellas. De allí, que la subregión de los Montes de María al estar comprendida por la parte montañosa de la Serranía de San Jerónimo, se convierte en la más rica en flora y fauna del departamento, situación que le permite contar con una invaluable riqueza de recursos naturales que hacen posible el turismo ecológico en la zona; en consecuencia, Colosó al ser uno de los municipios más beneficiados por su posición geo- 
gráfica, ha venido desarrollando diferentes actividades Ecoturísticas en el territorio, de lo cual resulta una explotación de turismo de naturaleza que favorece directamente a su economía; hecho que puede convertirse en ventaja competitiva turística, perdurable y auto sostenible para el departamento.

Asimismo, las subregiones de Sabanas y Montes de María, se destacan por la práctica del turismo de artesanías, considerándose estas actividades un atributo que las promueve como destino turístico en el departamento. Las referidas actividades, se encuentran integradas por entidades productoras y/o comercializadoras de productos artesanales, especialmente en los municipios de Sampués y Morroa; los cuáles se caracterizan por su arraigo en la actividad artesanal y su continua mejora en el manejo de materiales de caña flecha, madera, mimbre, hilos y cuero, así como en los diseños variados y coloridos.

El turismo de artesanías de Sampués y Morroa y el ecoturismo de Colosó, pueden aportar a la competitividad de un Sucre turístico; sin embargo, estas actividades actualmente no tiene mayor participación en el PIB del departamento, lo anterior, en razón de las deficiencias tanto internas como externas que existen en cada segmento turístico que impiden generar competitividad.

Por otro lado, algunos estudios han demostrado que en el turismo existen limitaciones en cuanto a herramientas que logren integrar la subjetividad y el conocimiento tanto tácito como explícito de actores (empresarios, clientes externos, internos, comunidad y entorno), que en un momento dado pueden configurar la dinámica de la experiencia turística tanto desde el punto de vista de la oferta como de la demanda. (Batista, Ronda, Torres \& Escalona, 2013); asimismo, limitaciones como los ambientes competitivas externos no monitoreados, los equipamientos y servicios ofrecidos (Cruz, Dos Anjos \& Joana, 2011).

En función de lo expuesto, determinados autores conciben a la inteligencia competitiva y tecnológica como elementos fundamentales para toda organización turística; esencialmente para la toma de decisiones estratégicas, se consideran herramientas de vital importancia la observación y el análisis del entorno científico y tecnológico (Calero, Parra \& Santana, 2010); Según Cavaller (2009), esta exploración del entorno, cubre no sólo a competidores, proveedores y clientes sino que también incluye tecnología, las condiciones económicas, el ambiente político y las tendencias sociales y demográficas. 
En consideración de lo expuesto, así como de las limitaciones que ostenta el departamento en términos de competitividad, se realizó el estudio para analizar la inteligencia comercial del turismo artesanal de los municipios de Sampués y Morroa, y el ecoturismo de la reserva natural de Colosó,

para conocer las condiciones actuales de mercado y determinar las propuestas para mejorar su competitividad análisis de inteligencia comercial y competitiva, donde se estudió con la finalidad de realizar una vigilancia estratégica del sector, que permita estudiar y analizar a cada uno de los agentes que intervienen en el mercado (cliente, producto, competidores y entorno), y sus condiciones actuales; y así poder determinar acciones para mejorar y fortalecer el potencial comercial tanto de las artesanías como el del ecoturismo.

\section{Marco teórico}

El turismo para poder contribuir al desarrollo económico y social de un territorio, debe generar competitividad, luego entonces, es esencial que la actividad turística produzca rendimientos económicos que le permitan realizar un aporte significativo al PIB de la región, para ello, se debe ofertar un producto turístico de calidad con un valor agregado que lo distinga en el mercado y satisfaga las expectativas de los turistas. Para Hassan (2000) la competitividad en turismo es la capacidad que tiene un destino para crear e integrar productos con valor añadido que permitan sostener los recursos locales y conservar su posición de mercado respecto a sus competidores.

Por otra parte, en cuanto a la vigilancia estratégica planteada, se puede decir que en los procesos de comercialización, la inteligencia comercial y competitiva actúa como medio para reducir las incertidumbres del mercado, al identificar las debilidades y amenazas del sector para luego convertirlas en oportunidades y fortalezas. De esta manera minimiza los riesgos y contribuye al buen desarrollo de los procesos comerciales.

El término de inteligencia competitiva es un área nueva del conocimiento y se puede afirmar que actualmente no ha alcanzado un marco bibliográfico compacto, entre las teorías planteadas acerca del tema, ésta es definida como: 
Un proceso analítico que transforma datos desagregados de los competidores, industria y mercado, en conocimientos aplicables a nivel estratégico, relacionados con las capacidades, intenciones, desempeño y posición de los competidores. Dicho proceso pretende dar un paso más al determinar qué información sobre el entorno es de mayor valor, qué medios utilizar, a quién recurrir, cómo transmitirla, y especialmente, cómo generar oportunamente un resultado incorporable a la toma de decisiones de la organización (Zaintek, 2003. p. 40).

Por otro lado, existe una nueva concepción de la inteligencia comercial, que no desplaza a la tradicional investigación de mercado, sino que es un concepto más amplio, que la complementa y la integra a otras fuentes de información; razón por la cual Méndez (2008) la define como el conjunto de métodos, técnicas y mecanismos para recabar, registrar, analizar y difundir la información estratégica sobre: la competencia, acciones del gobierno y el medio ambiente, su finalidad es permitir que la organización aproveche sus oportunidades y minimice sus riesgos.

Por su parte, Cavaller (2009) en su artículo Actualidad de la Inteligencia Competitiva, hace una recopilación de las definiciones más significativas que ha tenido la inteligencia competitiva, entre las cuales para esta investigación se consideran los planteamientos de Choo, quien asocia la inteligencia competitiva con la exploración del entorno, definiéndola como:

La adquisición y el uso de la información sobre acontecimientos, tendencias y relaciones en el entorno externo de una organización, cuyo conocimiento asistirá a la gerencia a planear la organización una línea de conducta futura. Las organizaciones exploran el ambiente en orden a entender fuerzas externas del cambio con el fin de desarrollar las respuestas eficaces para mejorar la propia posición en el futuro. La exploración cubre no sólo a competidores, proveedores y clientes sino que también incluye tecnología, las condiciones económicas, el ambiente político y las tendencias sociales y demográficas. (pág. 37)

Históricamente, para analizar el ambiente de competitividad y la implementación de estrategias, se ha adoptado por el proceso de inteligencia competitiva, en el que se ha determinado utilizar los siguientes métodos, análisis o herramientas: 
- Factores críticos de éxito: hace referencia a los factores que se les debe otorgar mayor atención en el proceso de análisis de inteligencia competitiva, puesto que son determinantes para alcanzar los objetivos de competitividad mediante la implementación de planes estratégicos que conlleven a la consecución de los mismos.

- Matriz SWOT: es utilizada para hacer un diagnóstico de la situación real del mercado, así mismo ayuda a mejorar e identificar las ventajas competitivas que éste presente.

- Benchmarking: "el proceso continuo de comparar los productos, servicios y prácticas con los más fuertes competidores o con las compañías reconocidas como líderes de la industria." (Balm 1995: 34).

- Modelo de las cinco fuerzas de Porter: mediante la cual, se expone que la competencia en un determinado segmento tiene sus raíces en las economías implícitas y en las fuerzas competitivas que van más allá de los competidores establecidos en cierto segmento Porter (2003: 95). Clientes, proveedores, competencia potencial, y productos substitutos, son todos competidores que pueden ser más o menos importantes o activos, dependiendo del segmento. (Citado en Estudios y Perspectivas en Turismo, vol. 20, núm. 2, 2011, pp. 478-498 "la inteligencia competitiva aplicada a las redes hoteleras brasileñas").

En el proceso desarrollado se pretendió utilizar para un análisis exploratorio de inteligencia competitiva, los enfoques teóricos referenciados con anterioridad, para describir las características de producción, comercialización, alcances de participación en el mercado y esquemas de gestión, que indican aspectos de competitividad y retos más relevantes, de los segmentos de negocios.

\section{Metodología}

En el artículo se muestran los resultados de una investigación cuantitativa de tipo descriptivo-analítica, de corte transversal desarrollada en los años 2015 y 2016. Se trabajó con entidades comercializadoras y/o manufactureras de artesanías en los municipios de Morroa y Sampués y personas gestoras del turismo ecológico en el municipio de Colosó. Para la selección de la muestra se aplicó un tipo de muestreo no probabilístico, en el cual se eligieron 33 establecimientos en Sampués, utilizando un muestreo intencional o de conveniencia; y 10 en Morroa, utilizando un muestreo de bola de nieve; en Colosó se estableció como muestra 
los participantes más representativos del ecoturismo, los cuales fueron alrededor de 15 personas y los instrumentos de recolección de información aplicados fueron: la observación, la entrevista semiestructurada y las encuestas, con las cuales se desarrollaron las siguientes fases del estudio: caracterización de los segmento de mercado del turismo de artesanías y del ecoturismo, análisis de las condiciones de competitividad, las relaciones de los agentes de mercado, eslabonamientos, redes de servicio, administración, infraestructura, sistemas de información y aplicación de las tecnologías de información y comunicación y realización de un Benchmarking, con base a los resultados obtenidos en la fase anterior, con entidades dedicadas al turismo de artesanías y el ecoturismo en la ciudad de Cartagena.

Los resultados se presentan a través de análisis independientes elaborados en cada área de estudio, acompañados de imágenes y gráficas que ilustran la situación actual de los mercado; posteriormente se contrasta la información obtenida mediante la realización del benchmarking y finalmente se establecen propuestas para mejorar la competitividad en los segmentos de turismo estudiados.

\section{Resultados}

\section{Análisis de competitividad del turismo de artesanías en el municipio de Sampués}

En el municipio de Sampués predominan los establecimientos artesanales de únicos dueños o empresas familiares (Figura 1), funcionando estos en un 94\% como microempresas, las cuales en su mayoría tienen más de 10 años en el mercado (Figura2).

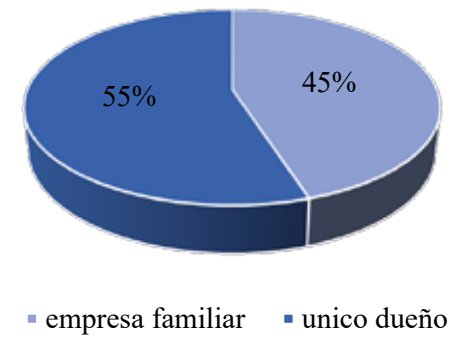

Figura 1: Tipo de establecimiento según propietarios

Fuente: Encuesta y elaboración propia. 


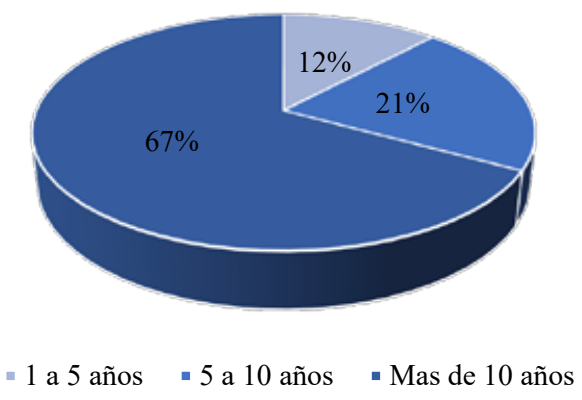

Figura 2: Permanencia en el Mercado Fuente: Encuesta y elaboración propia.

Los productos artesanales más ofertados y de mayor interés para los turistas, son los productos relacionado con la mueblería, artículos para decorar la casa, los tradicionales accesorios en caña flecha, las hamacas, columpios infantiles y la insignia del sombrero vueltiao (Imagen 1).

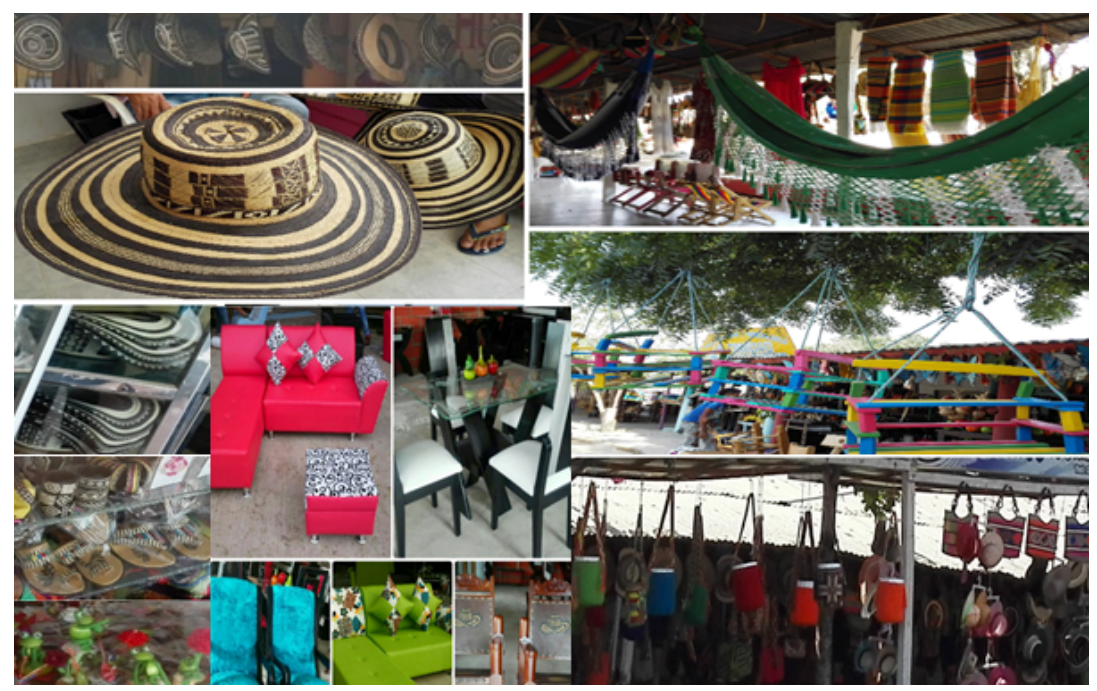

Imagen 1. Productos Artesanales de Sampués

Fuente: Fotos de ilustración autoría propia. 
El 58\% de las empresas de artesanías del sector turístico de Sampués, se encuentran enfocadas en adquirir una ventaja competitiva en el mercado a través de la oferta de un producto diferenciado en calidad y variedad del diseño artesanal, así mismo sus principales estrategias para competir, son la calidad, la innovación, el precio accesible, y la atención y publicidad.

En cuanto al entorno comercial, existe un ambiente de competencia desleal por parte de algunos competidores, que manifiestan no tener precios establecidos de acuerdo a la calidad del producto que ofrecen, lo cual genera, no solo una gran diferencia de precios en el mercado, sino una subvaloración de productos; puesto que ofertan bienes a un menor precio pero de menos calidad, lo que impide la venta de un producto verdaderamente calificado a un precio proporcional a su costo, originándose así una puesta en riesgo de la competitividad del sector de acuerdo a la fijación de precios competitivos.

El alcance de las ventas de las artesanías corresponde a un $80 \%$ a turistas regionales y nacionales, y un $20 \%$ a clientes internacionales; siendo el $64 \%$ de ellos compradores minoristas y un 36\% mayoristas. La época del año más visitada por los turistas son a fin de año (diciembre-enero), mediados de año (junio-julio), semana santa y la semana de vacaciones de octubre.

Los proveedores son $100 \%$ de procedencia local, solo el $12 \%$ afirmó hacer compras adicionales de sus materias primas a nivel regional y un $3 \%$ a nivel nacional, los motivos para escoger a sus proveedores son la cercanía, la calidad, los precios y la facilidad de pago.

Con respecto al origen de los recursos económicos de los establecimientos, los comerciantes artesanos acuden a realizar préstamos bancarios o a financiarse con fuentes externas en un $79 \%$, a continuación la distribución de la contribución del apalancamiento financiero. (Figura 3).

El sector artesanal de Sampués cuenta con una ubicación estratégica, puesto que las entidades productoras y comercializadoras de artesanías, se encuentran en una de las vías principales del departamento en la que se evidencia gran afluencia de turistas. Sin embargo, en aspectos de infraestructura interna el 52\% afirma no contar con el espacio e instalaciones locativas adecuadas para ofrecer sus productos. 


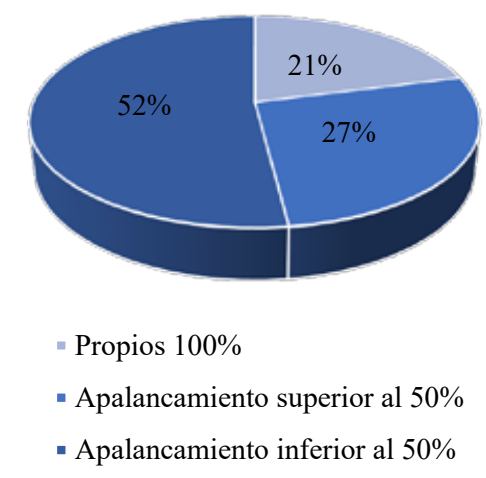

Figura 3: Origen de los Recursos Económicos

Fuente: Encuesta y elaboración propia.

Entre los competidores no existe registro significativo de alianzas estratégicas para generar mayor competitividad en el sector artesanal, de allí que el grado de asociatividad corresponde al 9\% del total de la población. Por otra parte, en el sector es bastante débil la planeación estratégica de la actividad turística artesanal, ya que el 97\% afirma no realizar ninguna de las fases del proceso administrativo en su negocio, limitando así el desarrollo de medidas o planes competitivos.

Sólo el 18\% de los comerciantes artesanos cuentan con herramientas tecnologías como el uso de teléfonos celulares, computadores y conexión de internet para el desarrollo de su actividad comercial. Por lo tanto, es muy bajo el nivel de implementación de las TIC en el sector para mejorar la competitividad, de hecho son escasos los establecimientos que tienen páginas web o hacen publicidad y promoción turística a través de internet.

A pesar del bajo nivel de competitividad que se refleja en el sector, un $88 \%$ de la población afirma haber tenido un crecimiento notorio en su actividad comercial en los últimos años, así mismo un 76\% considera que gracias a la calidad de los productos que ofrecen, se puede lograr competir con bienes importados. 


\section{Análisis de competitividad del turismo de artesanías en el municipio de Morroa}

En el municipio de Morroa predominan los establecimientos artesanales de únicos dueños o empresas familiares, funcionando estos en un 100\% como microempresas, de las cuales un $90 \%$ tienen más de 10 años en el mercado. Los principales productos artesanales que ofrecen son los elaborados en tejido, tales como las hamacas, sillas hamacas, columpios, mochilas, bolsos, gorros, pavitas, ponchos, bufandas, sandalias, zapatos, sobrecamas, cenefas, cortinas y centros de mesa; todos ellos elaborados en hilo (Imagen 2).

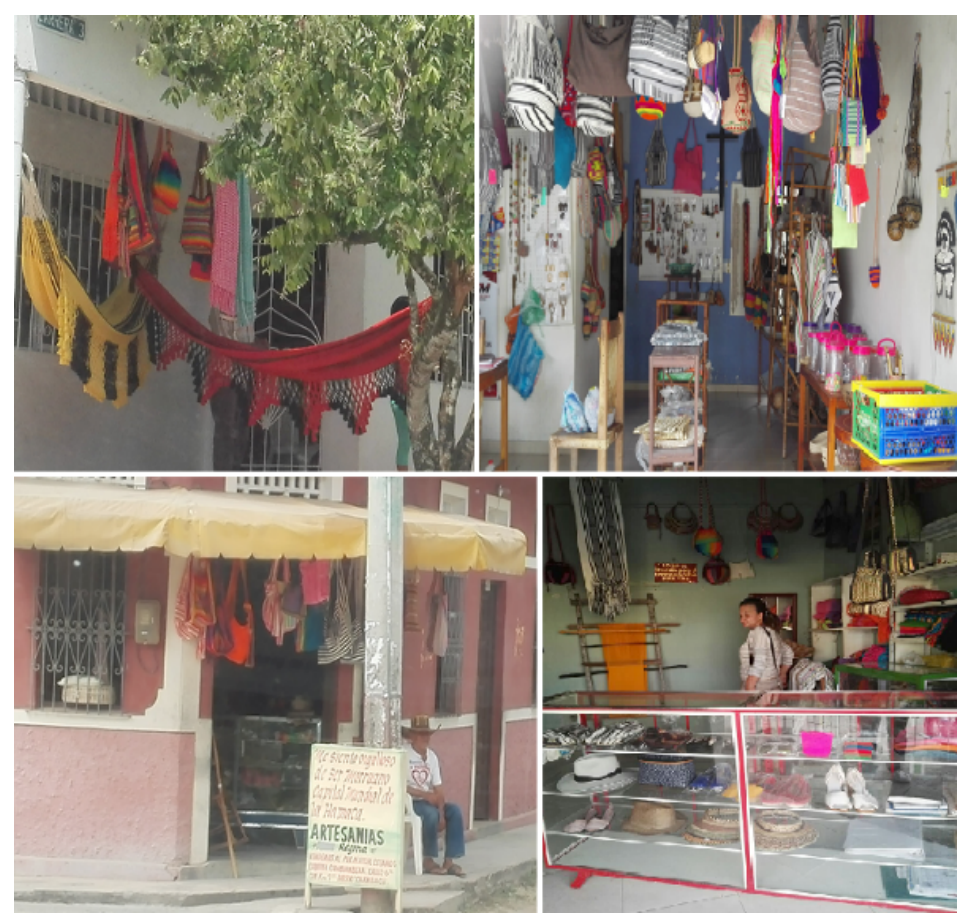

Imagen 2. Productos Artesanales de Morroa

Fuente: Fotos de ilustración autoría propia. 
El 40\% de las empresas de artesanías del sector turístico de Morroa, se encuentra enfocado en adquirir una ventaja competitiva en el mercado a través de la oferta de un producto diferenciado en calidad de tejido y en la elaboración de nuevos productos, de allí que sus principales estrategias para competir, son la calidad, la innovación y el precio accesible de sus artesanías.

Un 70\% de los artesanos consideran que los precios que ofrecen en el mercado de turismo de artesanías son competitivos, guarda relación el esfuerzo impreso en cada tejido con el dinero recibido; sin embargo el otro 30\% de la población, afirma no percibir el costo beneficio esperado en sus ventas, debido a que no cuentan con el capital de trabajo suficiente que les genere solvencia económica para acelerar su proceso de elaboración de artesanías, por lo tanto, deben vender a un precio más bajo para poder continuar con su actividad económica.

El alcance de las ventas de las artesanías de Morroa es de nivel nacional, regional e internacional, según orden de importancia, lo que indica que son mayores las ventas generadas hacia el interior del país, no obstante las ventas a turistas extranjeros también son significativas. En este sentido, también es preciso mencionar que en un $60 \%$ las ventas se realizan a turistas minoritas y en una proporción del $40 \%$ son ventas al por mayor.

Los proveedores en su gran mayoría son de procedencia regional o nacional, el 40\% de los comerciantes artesanales compran parte de sus materias primas a nivel local.

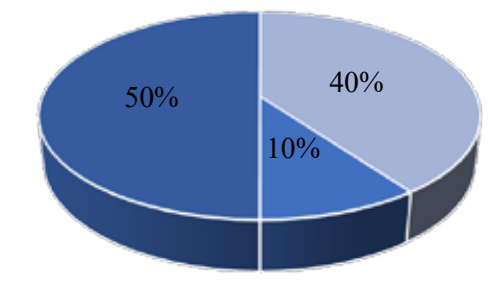

- Propios 100\%

- Apalancamiento financiero superior al 50\%

- Apalancamiento financiero inferior al 50\%

Figura 4: Origen de los Recursos Económicos Fuente: Encuesta y elaboración propia. 
En cuanto al origen de los recursos económicos de los comerciantes artesanos, el 90\% se financian en su gran mayoría con recursos propios y un 10\% tiene comprometido en más de un 50\% su capital de trabajo con fuentes de financiación externa, a continuación se indica la contribución del apalancamiento financiero en los negocios (Figura 4).

Todo el sector artesanal cuenta con buenas vías de acceso externas para llegar al municipio, el cual se encuentra a 5 minutos de la capital del departamento, sin embargo, las vías internas del municipio no gozan de una adecuada infraestructura. Seguido de ello, se puede decir que el $60 \%$ de los consultados afirman no contar con las instalaciones locativas óptimas para brindar un buen servicio de turismo.

Entre los competidores no existe registro significativo de alianzas estratégicas para generar mayor competitividad en el sector artesanal, de allí que el grado de asociatividad corresponde al $10 \%$ del total de la población. Por otra parte, se puede decir, que en el sector tampoco existe una planeación estratégica de la actividad turística artesanal, ya que el 90\% afirma no realizar ninguna de las fases del proceso administrativo en su negocio, limitando así el desarrollo de medidas o planes competitivos.

En términos de implementación de las tecnologías de información y comunicación TIC, los artesanos de Morroa manifiestan tener poco conocimientos en el área, sus redes de contacto surgen a partir del uso del teléfono celular, lo cual indica, que están utilizando escasos recursos tecnológicos que les permita promocionar y publicitar su potencial turístico artesanal en otros mercados, mediante la creación y el uso de páginas web y los beneficios del marketing virtual.

Finalmente, el $80 \%$ de la población afirma haber tenido un crecimiento notorio en su actividad comercial en los últimos años, y justamente ese mismo porcentaje considera que por sus exclusivos tejidos a mano y de buena calidad, se puede lograr competir con bienes importados.

\section{Análisis de competitividad del ecoturismo del municipio de Colosó}

El ecoturismo de Colosó, se desarrolla a partir de la privilegiada ubicación del municipio en los montes de maría, lo cual representa una riqueza paisajística que resulta de una combinación perfecta de la naturaleza, formada principalmente por sus arroyos y paisajes montañosos; de dicha combinación surgen los principales atractivos turísticos: 
- Las famosas "Pozas de Colosó" también conocidas como las piscinas naturales del departamento de Sucre, son alrededor de 13 pozas, las cuales se forman en el lecho del arroyo de Colosó.

- Bosque Monte Mariano, gracias a los recursos naturales que brinda el mercado turístico se puede disfrutar de recorridos por los cerros, conocer las hermosas montañas representativas de los montes de maría y observar la fauna viviente en la zona.

- El lugar mágico del "Salto del Sereno", es una cascada de aproximadamente 20 metros de altura, la cual se forma de una fuente de agua natural, logrando consigo un bello paisaje, donde se puede presenciar la caída del agua cristalina que se desprende desde lo alto de una gran roca y reposa en la superficie formando una piscina natural de agua fría que se encuentra rodeada de piedras de diferentes tamaños.

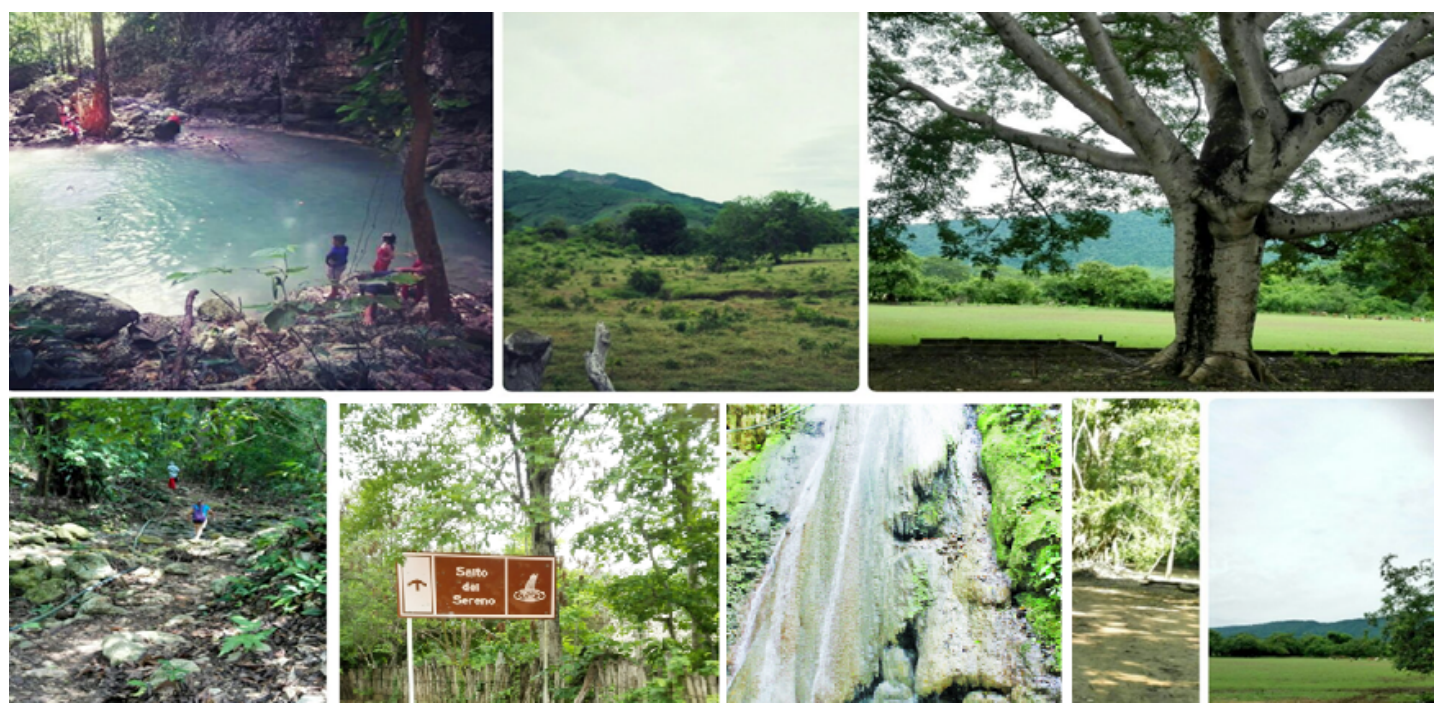

Imagen 3. Salto del Sereno

Fuente: Fotos de ilustración autoría propia.

Las principales actividades de naturaleza que puede desarrollar un turista en la reserva natural del municipio de Colosó son: bañarse en las aguas de los ríos (los diferentes balnea- 
rios naturales), realizar paseos ecuestres, contemplar la rica fauna tropical, recrearse con el bello paisajismo (hacer tomas fotográficas),realizar rutas de senderismo, caminar por los bosques y disfrutar de la naturaleza, recorrer los montes de maría en bicicleta como actividad deportiva, hacer campamentos (en ocasiones los turistas se quedan acampar, hacen fogatas y disfrutan de los animales nocturnos del bosque).

Los principales actores que intervienen en el mercado turístico son:

- Guías Turísticos: son alrededor de 7 personas capacitadas para brindar orientación en la zona ecoturística.

- Organización de Comercio Ecoturístico: este grupo lo integra principalmente las personas responsables de los dos restaurantes de la zona, seguido de ello, los responsables del servicio de limpieza y parqueo y finalmente los vendedores de mecatos, bebidas y demás productos, comercializados alrededor de las pozas.

- Prestadores del servicio de transporte: conformado por las personas que brindan los paseos ecuestres y en tractor como servicio propio de la actividad ecoturística, adicional a ello también se encuentran los de transporte externo como los moto taxis y conductores de los carros antiguos jeep.

La actividad ecoturística que se desarrolla en el municipio, surge de la iniciativa privada de los principales actores de mercado mencionados anteriormente, quienes son los principales responsables de que hoy día exista este tipo de turismo representativo en la zona.

Actualmente, el municipio no cuenta con una infraestructura adecuada para brindar su servicio, puesto que, es un territorio de pendientes pronunciadas y de gran cantidad de escorrentías naturales, lo cual genera un constante deterioro del sistema vial. Razón por la cual, se espera que el gobierno emprendan proyectos que subsanen esta dificultad.

La implementación de las TIC en el mercado Ecoturístico, es muy escasa, sus principales agentes desconocen en gran proporción el tema, y a nivel general la publicidad que se le da al territorio es el "voz a voz" de los visitantes que ya tuvieron la oportunidad de conocer el territorio y disfrutar del turismo natural que en él se desarrolla. 
Lo anterior, evidencia limitadas redes de comunicación y servicios que apoyen este tipo de comercio, y por su parte no se implementan cadenas de contactos y estrategias de marketing que promocionen y atraigan mayor número de turistas al sector, de igual forma, no existe ningún tipo de alianzas para generar mayor competitividad en él.

\section{Benchmarking con entidades turísticas de la ciudad de Cartagena}

El benchmarking se desarrolló a partir de dos instituciones importantes de turismo en la ciudad de Cartagena, Distrito Turístico y Cultural. Para efectuar el análisis del turismo de artesanías se seleccionó a la fundación TUCULTURA y para realizar la contrastación del ecoturismo se visitó a la empresa turística ECOTOURS BOQUILLA.

TUCULTURA: su objetivo principal va más allá de ofrecer un destino turístico, busca proyectar, promocionar y fortalecer la cultura y el bienestar de los artesanos, promoviendo el desarrollo social y económico desde el sector cultural para un tejido empresarial competitivo en dirección a un turismo cultural sustentable, en el cual se encuentra el turismo de artesanías como un valor agregado del mismo. Un aspecto relevante de esta institución para implementar en el departamento de Sucre, es la creación de organizaciones que le apuesten a un turismo sostenible, es decir, que no estén enfocado solo a generar ingresos, sino también a fomentar empleos para la población y a su vez que sus dirigentes estén comprometidos a trabajar conjuntamente con la comunidad por el ambiente y la cultura de la región.

Esta organización recibe apoyo de importantes instituciones tanto internacionales y nacionales como regionales, tales como: la Organización de Estados Iberoamericanos para la Educación, la Ciencia y la Cultura (OEI), la Agencia Española de Cooperación Internacional para el Desarrollo, el Ministerio de Cultura de la República de Colombia, entre otros; a diferencia del turismo de artesanías sucreño que actualmente no recibe apoyo de ninguna institución.

Mientras el turismo en Sucre se desarrolla a partir de una necesidad económica de la población, los artesanos cartageneros al estar involucrados en un proyecto de for- 
mación cultural, visionan las artesanías más que una actividad comercial, como un servicio de turismo que tiene implícito la venta de sus creaciones, pero lo verdaderamente importante es generar ingresos para su población desde una perspectiva general, es decir, atraer a un cliente que le genere rentabilidad a largo plazo, cree permanencia y valore el trabajo turístico que desarrollan. A diferencia del turismo de artesanías sucreñas, los artesanos de Cartagena si realizan el proceso administrativo de su actividad comercial, tienen mayor organización y proyección en el mercado.

En términos generales de infraestructura y redes de servicios, la ciudad amurallada cuenta con su gran patrimonio histórico y cultural de reconocimiento universal y acervo de mayor desarrollo; también un contexto urbano de mejores vías, estructura externa e interna adecuada para llevar a cabo la actividad artesanal. Además redes de contacto, apoyo en las TIC, utilización de páginas web que facilitan la promoción e implementación de estrategias de marketing para el turismo y sin lugar a duda un apoyo fundamental para este segmento de negocio como lo es el de entidades estatales.

ECOTOURS BOQUILLA: su principal objetivo es brindar un producto de alta calidad, seguro y sostenible; sus actividades turísticas se fundamentan no solo en generar ingresos económicos para la comunidad, sino también en la preservación, protección y cuidado del ecosistema, para ello han distribuidos varios puntos ecológicos en el sector, desarrollado campañas de educación ecológica y actividades de limpieza. Lo anterior, sirve de referente para el ecoturismo que se desarrolla en la reserva natural de Colosó, puesto que resulta ser una buena iniciativa generar competitividad en el territorio a través de una perspectiva de turismo sostenible.

Esta institución evidencia un alto grado de organización y buena gestión por parte de sus directores, lo cual les ha permitido ofrecer un paquete turístico estructurado que satisface la demanda del turismo tanto nacional como extranjero. La actividad Ecoturística desarrollada en la Boquilla les ha permitido la creación de redes de servicios a partir de la implementación de las TIC, haciendo uso de su página web donde han logrado crear su propia red de contactos, hecho que les ha abierto puertas hacia diferentes mercados, que a su vez, les ha funcionado como medio de promoción y estrategia de marketing, al igual que las alianzas establecidas con las agencias de viajes y el sector hotelero. 


\section{Propuestas para mejorar competitividad}

- Propuestas para mejorar la competitividad en el turismo de artesanías de Sampués y Morroa

- Generar alianzas para competir sanamente en el mercado: una de las principales preocupaciones de los artesanos, especialmente los del municipio de Sampués, es tener que competir en un mercado donde se subvalora los productos de calidad, lo que genera una desproporcionalidad en los precios ofertados y un desequilibrio de las cargas costo/ beneficio. Ante esta situación es muy complejo generar competitividad en el sector, ya que existen desigualdades en términos de oferta, lo que ocasiona un choque en el entorno comercial, y una competencia desleal que impide cualquier tipo de alianzas y unión empresarial. Es por esta razón, que para superar dicha limitante, es necesario primero crear conciencia comercial entre los artesanos, que ellos reconozcan la importancia de sus artesanías y le den el valor a las mismas; como segunda medida se hace necesario crear planes estratégicos de comercialización que unifiquen los conceptos de calidad y precio, los cuales son directamente proporcional en términos de creación de rentabilidad, y finalmente proponer alianzas entre ellos para lograr un trabajo colectivo que proyecte competitividad en la zona artesanal.

- Direccionar las artesanías hacia el mercado nacional e internacional mediante la identificación de perfiles turísticos: es importante cambiar la perspectiva local que se tiene en cuanto a la comercialización de productos artesanales, ya que no han identificado un perfil de turista nacional y extranjero que se convierta a futuro en un cliente constante y no sólo en un visitante accidental; así las cosas, se debe enfocar las artesanías hacia un mercado más amplio, donde el turista que llegue lo haga porque se ha creado una marca y un reconocimiento de las artesanías sucreñas en el mundo comercial.

- El plan de acción a iniciar, debe ir direccionado a crear un producto que satisfaga las expectativas del turista y para ello se deben identificar varios perfiles de clientes. Lo cual será posible con estudios de mercado que se realicen en la zona, apoyados en gran medida en la información fundamentada en la experiencia de los artesanos, la implementación del buzón de sugerencias e implementación de herramientas que permitan determinar el grado de satisfacción del cliente ante el servicio ofertado, y conocer sus expectativas, gustos e intereses. 
- Saber competir para ser competitivos: el secreto de todo buen comerciante no es luchar contra la competencia, es saber vender y satisfacer a los clientes. Durante el desarrollo de la investigación base del presente artículo se encontró que existe una idea errada de competencia entre los mismos artesanos, el principal objetivo de ellos es vender más que el otro no importando el costo/beneficio de su venta. Ante esta situación es imposible generar competitividad en estas empresas, ya que se encuentran arriesgando su permanencia en el mercado al confundir los términos de ganancia con rentabilidad. Por lo cual, resulta fundamental capacitar a los artesanos en técnicas de comercialización, fijación de precios, trabajos de calidad y sobre todo en materia de competencia en el entorno comercial, puesto que, si bien, el objetivo es crear un área de turismo de artesanías competitivo en el departamento de Sucre, antes se hace necesario contar con un mercado unido que trabaje en conjunto bajo los términos de competencia leal, es decir, para proyectar un sector competitivo, primero deben serlo cada institución que integra dicho sector.

- Mejorar la infraestructura interna de cada establecimiento y la externa de todo el sector: en cuanto a la infraestructura del sector turístico artesanal, se puede mirar desde dos puntos de vistas: en primera instancia, la interna, que hace referencia a cada empresa artesanal, las cuales en su gran mayoría expresaron tener en sus planes y proyectos futuros invertir en mejoras de infraestructura en sus establecimientos e instalaciones locativas, ya que si bien es cierto más que locales comerciales, son casas familiares donde ofrecen sus productos. En segunda instancia, y como aspecto de mayor relevancia, es la infraestructura externa, la cual hace referencia a las vías de acceso, medios técnicos y servicios para desarrollar la actividad turística comercial. Ambos municipios cuentan con buenas vías de acceso para llegar al territorio, sin embargo, la infraestructura de cada lugar tiene su propia necesidad. Para el caso de Morroa, es necesario mejorar aspectos de ubicación y señalización de los establecimientos dentro del municipio, y en Sampués es indispensable la creación de un corredor turístico que les permita a los turistas transitar de manera segura mientras hacen su recorrido por todo el sector artesanal. Por ende, es necesario contar con el apoyo estatal para realizar este tipo de proyectos de inversión pública. 
- Creación de rutas de establecimientos para la comercialización de artesanías: resulta de gran utilidad para los turistas y establecimientos comerciales, que existan unas guías o rutas turísticas que indiquen la ubicación de cada empresa artesanal, de igual forma que en ella se contemplen datos como: el nombre, la dirección, los teléfonos y los principales productos oferentes. Lo anterior, con el fin de crear un registro de las entidades dispuestas a ofrecer un servicio turístico de comercialización de productos artesanales en el departamento, que a su vez facilite el comercio, la organización de los artesanos y la ubicación del turista en la región.

- Capacitaciones en tecnologías de la información y la comunicación (TIC): la implementación de estas tecnologías, es de vital importancia en el sector empresarial, y para el caso del comercio de las artesanías no es la excepción, por lo tanto, se recomienda capacitar al personal de los establecimientos de comercio en lo concerniente al uso y los beneficios que trae consigo la implementación de las TIC en la actividad turística artesanal.

- Registro de actividades y gestión de control: toda actividad comercial debe registrar sus operaciones para lograr tener un control de su gestión, esto permitirá conocer sus movimientos de ventas, gastos, ingresos, ganancias netas, inventario y capital de trabajo; que en su conjunto harán posible la toma de mejores decisiones para reinvertir el patrimonio, aumentar las utilidades, conocer la rotación de la mercancía, generar rentabilidad, entre otros beneficios. El registro de las actividades es fundamental para las empresas, ya que sin ellos no puede existir una planificación estratégica fundamentada en hechos reales que facilite completar el proceso administrativo en todas sus fases.

- Planes para generar marca y certificación de calidad: la elaboración y el diseño artesanal de los productos sucreños merecen tener su reconocimiento nacional como artesanías colombianas, por lo tanto, se debe trabajar en conjunto para crear una marca tanto de las artesanías de Morroa como las Sampuesanas, por ende se debe proyectar el trabajo de los artesanos hacia la certificación de calidad.

- Sitios web como medio de publicidad y marketing: las herramientas de las páginas virtuales, con el transcurrir del tiempo se han convertido en un medio publicitario de fácil acceso y de bajo costo económico, el cual contribuye a obtener un reconocimiento comercial en mercados nacionales e internacionales, mediante el cual se pueden promocionar los productos, crear redes de contactos y atraer nuevos clientes. 
- Apoyo gubernamental: los artesanos manifiestan que la población artesanal del departamento de Sucre no ha recibido mayores incentivos para desarrollar la actividad por parte del gobierno, puesto que manifiestan que no la tienen en cuenta como un servicio turístico representativo del departamento si no como una actividad comercial. No obstante, las artesanías sucreñas para generar competitividad regional deben ser apoyadas por el estado, tanto en proyectos de inversión de infraestructura, maquinaria, como reconocimientos en sus planes de promoción y capacitaciones de personal.

- Promover alianzas público/privadas que apoyen el mercado turístico de artesanías: es necesario implementar proyectos en el departamento de Sucre que gestionen alianzas de instituciones público/privadas, como Artesanías de Colombia, ANATO y agencias de viajes, que estén dispuestas apoyar el turismo de artesanías de la región, tanto promocional como económicamente y que a su vez cumplan la función de vitrina publicitaria que promueva el reconocimiento de las artesanías sucreñas en otros mercados.

\section{- Propuestas para mejorar la competitividad en el ecoturismo de Colosó}

- Realizar campañas de concientización ecológica y capacitación sobre el cuidado y preservación del ambiente: es importante en este tipo de turismo ecológico donde su principal atractivo es la naturaleza, construir respeto y conciencia ambiental en pro de la conservación de todos los recursos naturales, razón por la cual se debe trabajar en conjunto con la comunidad y estado para adquirir la responsabilidad de cuidar y preservar la reserva natural del municipio de Colosó. A partir de lo descrito, resulta fundamental empezar a minimizar los impactos negativos para el ambiente que genera la referida actividad turística. Una vez adquirido el compromiso por la colectividad, se debe iniciar el proceso de sensibilización con la población, para ello se debe trabajar con todas las personas que intervienen en este segmento: habitantes, agentes turísticos y visitantes. Luego entonces, se podrán llevar a cabo la implementación de puntos ecológicos, días de limpieza y demás actividades ambientales que contribuyan al desarrollo de un turismo ecológico sostenible.

- Seguridad en equipos del guía turístico: si bien es cierto el municipio cuenta con alrededor de 7 guías turísticos capacitados para ofrecer el servicio de acompañamiento y orientación, éstos no tienen el equipaje necesario para desarrollar dicha actividad. 
Actualmente, las personas desempeñan su labor sin ningún elemento de protección o cuidado para evitar cualquier tipo de riesgo, ya sea un botiquín de primeros auxilios, botas o calzado adecuado para el bosque y la zona montañosa, vestimenta apropiada, elementos de comunicación como radioteléfonos, entre otros. Ahora bien, para continuar con el desarrollo de la actividad ecoturística en el municipio, es de vital importancia que estas personas tengan seguridad en equipos de guías turísticos, según la norma técnica colombiana NTC-OSHAS 18001 sistema de gestión en seguridad y salud ocupacional, ratificada en el 2007. Seguridad "es la condición de estar libre de riesgo y que éste produzca un daño inaceptable", razón por la cual, es necesario el conocimiento, aplicación y buen manejo de equipos pertinentes al guía de turismo

- Identificación de los guías turísticos: resulta de gran ayuda para los turistas tener identificado al personal capacitado para llevar a efecto la labor, esto genera confianza a los visitantes. Por otra parte, es fundamental que exista un registro de los datos principales de estas personas, para que en casos fortuitos o de emergencia, se tenga total certeza de sus nombres, cédulas, nombre de la entidad promotora de salud a la que pertenecen, tipo de sangre, números telefónicos, domicilios y contacto de la persona o pariente a la cual recurrir.

- Inversión en proyectos de hospedaje y alojamiento: la actividad del ecoturismo está siendo enfocada actualmente para generar ingresos por una única estadía del turista en el municipio, es decir, el turismo se está proyectando sólo por un día, puesto que no existen establecimientos de hospedaje que le brinden la oportunidad al turista de quedarse por más tiempo; sin embargo, en algunas ocasiones se hospedan en las casas de los habitantes de la zona, que durante la época de vacaciones son adecuadas como hoteles. En función de ello, resulta necesario emprender planes efectivos que proyecten a Colosó como un centro turístico que ofrezca un servicio completo: tanto Ecoturístico como de alojamiento; enfocado este último en proyectos de inversión con infraestructura adecuada para el hospedaje de los visitantes y de esta manera incrementar el tiempo de estadía de los mismos en la región, lo cual significa mayor satisfacción para el turista, mayores ingresos para el municipio y desarrollo para el departamento. 
- Construir una adecuada infraestructura vial: el municipio no cuenta con la infraestructura adecuada de drenaje para las vías, en consecuencia de ello, se presentan graves problemas de movilidad, afectándose de esta manera la comunidad en general y creándose una limitación para la llegada del turista. Es fundamental que existan programas de mantenimiento de las vías, en conjunto con proyectos de inversión estatal que le apunten a suplir esta necesidad.

- Apoyo Gubernamental: de acuerdo con la información suministrada por los principales actores turísticos, existe un inconformismo por parte de la comunidad, referente al poco o esporádico apoyo recibido por parte del gobierno; puesto que como se ha venido desarrollando la temática, la actividad turística en gran medida es efectiva gracias a la iniciativa particular y voluntaria de los habitantes, quienes han asumido todos los costos de gestión y organización.

- Capacitación del personal: los principales agentes que intervienen en el mercado turístico de la región, son personas que no alcanzaron a terminar sus estudios de bachillerato, lo cual refleja en ellos una débil formación educativa; sin embargo, cuentan con cualidades destacables que han hecho posible el desarrollo del ecoturismo como actividad comercial, es por esta razón, que resulta importante resaltar que el espíritu emprendedor y la amabilidad de estas personas son los fundamentos de este segmento de negocio. Ahora bien, si se desea mirar el ecoturismo como una fuente potencial generadora de ingresos para el municipio que genere competitividad en el departamento, es necesario visionar este tipo de turismo en planes estratégicos de comercialización, lo que implica capacitar al personal en aspectos tales como: atención y servicio al cliente, cursos de gastronomía diversa, técnicas en ventas y negociación, manejo de las tecnologías de información y comunicación, dominio básico de lengua extranjera como el inglés, cursos de atención a emergencia y primeros auxilios, formación calificada de guías turísticos, promoción y marketing del turismo, campañas de sensibilización de cuidado al medio ambiente y comportamiento adecuado con la naturaleza, entre otros.

- Creación de rutas o tours: la actividad Ecoturística debe contemplar un paquete de oferta completo y organizado, para ello es necesario crear diferentes rutas que logren satisfacer las expectativas de los distintos perfiles identificados de los turistas. 
- Creación de un sitio web y aplicación de nuevas tecnologías: esto impacta de manera positiva las ventas, la productividad y el valor de mercado de las organizaciones, puesto que el uso del internet y sus herramientas cibernéticas permite el alcance de nuevos clientes de forma masiva y sencilla.

- Fomentar alianzas público/privadas que apoyen el ecoturismo: es necesario implementar proyectos que gestionen este tipo de alianzas para que apoyen tanto promocional como económicamente el turismo; entidades como agencias de viajes y promoción turística, que promuevan el reconocimiento del ecoturismo en mercados nacionales e internacionales y contribuyan a crear redes de servicios.

\section{Conclusiones}

Como aspectos concluyentes del análisis realizado a las actividades turísticas de artesanías y de ecoturismo desarrolladas en el departamento de Sucre, se determina que a pesar de tener un gran potencial turístico, este no ha sido explotado de la forma adecuada para generar competitividad. Han enfocado su actividad en la generación de ganancias y no de rentabilidad, se interesan en producir ingresos en un tiempo inmediato que no permite crear planes de crecimientos e inversiones futuras.

Actualmente el turismo del departamento tiene escaso respaldo por entidades público privadas que contribuyan con su desarrollo, convirtiéndose esto en una limitante para fomentar proyectos de inversión enfocados en la mejora de infraestructura y redes de servicios. Asimismo, se logró contrastar que la creación de alianzas en el mercado turístico es trascendental para consolidar el mercado y establecer políticas de calidad, fijación de precios y reglas de competencia sana en el entorno comercial.

Los servicios turísticos ofertados en los municipios de Morroa, Sampués y Colosó, presentan limitantes importantes para satisfacer en términos generales la demanda turística del mercado, por lo que resulta necesario emprender planes estratégicos orientados a elaborar un producto turístico integral, de valor agregado y calificado. En tal sentido, el segmento de negocio de turismo debe apostarle a un mercado nacional e internacional, proyectar sus servicios a esferas globales y crear redes de contactos que faciliten ampliar el mercado y adquirir nuevos clientes. Es importante mencionar que las tecnologías de información y comunicación son necesarias para implementar sistemas de información y efectuar planes de promoción y marketing virtual. 
Finalmente, con los resultados obtenidos queda evidenciado que las entidades y principales agentes del turismo de artesanías y del ecoturismo en Sucre, no realizan estudios de inteligencia comercial y competitiva en el desarrollo de sus actividades; asimismo el departamento carece de antecedentes en este tipo de estudios. En función de ello, el presente artículo resulta de gran valor para futuras investigaciones, ya sea para aplicar el análisis de inteligencia comercial y competitiva al mismo tipo de turismo en diferentes territorios, elaborar nuevos análisis en un segmento de mercado distinto o en otra clase de turismo (cultural, gastronómico, de sol y playa, etnoturismo entre otros). En este sentido, el trabajo investigativo crea un precedente para determinar y guiar futuras líneas de investigaciones sobre temas relacionados en el presente estudio, tales como: sistemas de inteligencia de mercados, planes estratégicos de competitividad, servicios turísticos, sistemas de calidad y caracterización de los lugares o población estudiada similar.

\section{Referencias}

Balm, J. (1995). Benchmarking: um guia para o profissional tornar-se - e continuar sendo -o melhor dos melhores. Rio de Janeiro: Qualitymark.

Batista, C., Ronda, G., Torres, Y. y Escalona. R. (2013). Evaluación de la visión y las expectativas de los actores de un destino turístico Caso de estudio Destino Holguín. Cuba: Estudios y perspectivas en Turismo.

Calero, F. Parra, E. y Santana, A. (2010). Vigilancia tecnológica e inteligencia competitiva: un análisis de la demanda tecnológica en alojamientos turísticos en canarias. Recuperado de: http://www.aecit.org/jornal/index.php/AECIT/article/view/31/28.

Cavaller, V. (2009). Actualidad de la Inteligencia Competitiva. Cuadernos de Inteligencia Competitiva, Vigilancia Estratégica, Científica y Tecnológica QUIC\&VECT, 2 (1). 31-44.

Cruz, F. Dos Anjos, G. y Joana, S. (2011). La inteligencia competitiva aplicada a las redes hoteleras brasileñas. Estudios y Perspectivas en Turismo, 20 (2). 478-498.

Gobernación de Sucre \& fondo de promoción turística Colombia. (2011). Plan Estratégico de Desarrollo Turístico 2011-2020.

Hassan, S. (2000). Determinants of market competitiveness in an environmentally sustainable tourism industry. Journal of Travel Research, 38:239-245. 
Mejía. I. (2013). Propuesta de turismo activo experiencial para el municipio de Colosó - Sucre. Universidad tecnológica de bolívar. Cartagena de Indias. Recuperado de http://biblioteca. unitecnologica.edu.co/notas/tesis/0064109.pdf.

Méndez, C (2008). Inteligencia Comercial. Taller de Informática aplicada a los Negocios. http://www.authorstream.com/Presentation/cmendez-1407334-inteligencia-comercial-definitivo/

Mier, M. (2002). Inteligencia competitiva: un factor importante para construir una tradición tecnológica. Recuperado de http://www.iie.org.mx/bolDPATY02/tec2.pdf.

Ministerio de Comercio Industria y Turismo \& Cámara de Comercio de Sincelejo. (2009). Plan regional de competitividad del departamento de sucre.

Ortega. L. y Romero. J. (2008). Estudio de factibilidad para la comercialización y distribución de productos artesanales a base de totumo en el corredor artesanal de Sampués. Recuperado de http://repositorio.unisucre.edu.co/bitstream/001/374/2/658.835077.pdf.

Porter, M. (2003). Como as forças competitivas moldam a estratégia. En: Mintzberg, H. Lampel, J. Quinn, J. B. Ghoshal, S. O. processo da estratégia. Bookman, Porto Alegre. 27- 45.

Salim. L. y Carbajal, R. (2006). Competitividad: marco conceptual y análisis sectorial para la provincia de Buenos Aires. Recuperado de http://www.ec.gba.gov.ar/prensa/Archivos/ Cuaderno74.pdf.

Sánchez. M. y Fajardo, M. (sf). La competitividad de los destinos turísticos: un análisis cuantitativo mediante modelos logísticos. Aplicación a los municipios extremeños. Recuperado de http://fama2.us.es:8080/turismo/turismonet1/economia\%20del\%20turismo/mercados\%20turisticos/competitividad\%20de\%20los\%20destinos\%20turisticos.pdf.

Velasco. M (2009). Gestión turística del patrimonio cultural: enfoques para un desarrollo sostenible del turismo cultural. Cuadernos de Turismo, 23. 237-254.

Zaintek, (2003). Guía de vigilancia tecnológica: Sistema de información estratégica en las pymes. Zaintek. Servicio de vigilancia tecnológica e inteligencia competitiva. Bilbao. Recuperado de: http://www.fundacionede.org/gestioninfo/docs/contenidos/_guiazaintek_.pdf. 